\title{
Communication
}

\section{Morphological Anomaly in the Scutum of Bichromomyia olmeca bicolor (Diptera: Psychodidae), Captured in Iñapari Town, Trinational Border Peru, Brazil and Bolivia}

\author{
Antônio Luís Ferreira de Santana ${ }^{1}$, Rodrigo Espindola Godoy ${ }^{1}$, Nataly Araujo Souza ${ }^{1}$, \\ Júlia dos Santos Silva ${ }^{2}$, Gloria Minaya Gómez ${ }^{3}$, Nyshon Rojas Palomino ${ }^{3}$, \\ Carlos Magallanes Benavides ${ }^{4}$, Abraham Germán Cáceres ${ }^{5,6}$, Monica Guardo ${ }^{7}$, \\ Alfredo Carlos Rodrigues de Azevedo, ${ }^{1, *}$ \\ ${ }^{1}$ Interdisciplinary Entomological Surveillance Laboratory in Diptera and Hemiptera, Oswaldo Cruz Institute, Oswaldo Cruz Foundation, Rio de \\ Janeiro, Brazil \\ ${ }^{2}$ Diptera Laboratory, Oswaldo Cruz Institute, Oswaldo Cruz Foundation, Rio de Janeiro, Brazil \\ ${ }^{3}$ National Reference Laboratory for Leishmaniasis, National Institute of Health, Lima, Peru \\ ${ }^{4}$ Iñapari Health Post Regional, Executive Direction of Peripheral Health Networks, Government of Madre de Dios, Iñapari, Peru \\ ${ }^{5}$ Entomology Laboratory of the National Institute of Health, Chorrillos, Peru \\ ${ }^{6}$ Entomology Section, Institute of Tropical Medicine "Daniel A. Carrión" and Academic Department of Medical Microbiology, Faculty of \\ Human Medicine, Universidad Nacional Mayor de San Marcos, Lima, Peru \\ ${ }^{7}$ Department of Communicable Diseases and Environmental Determinants of Health, Pan American Health Organization, Lima, Peru
}

Email address:

alcaraze@ioc.fiocruz.br (A. C. R. de Azevedo)

${ }^{*}$ Corresponding author

\section{To cite this article:}

Antônio Luís Ferreira de Santana, Rodrigo Espindola Godoy, Nataly Araujo Souza, Júlia dos Santos Silva, Gloria Minaya Gómez, Nyshon Rojas Palomino, Carlos Magallanes Benavides, Abraham Germán Cáceres, Monica Guardo, Alfredo Carlos Rodrigues de Azevedo. Morphological Anomaly in the Scutum of Bichromomyia olmeca bicolor (Diptera: Psychodidae), Captured in Iñapari Town, Trinational Border Peru, Brazil and Bolivia. American Journal of Entomology. Vol. 4, No. 2, 2020, pp. 35-38. doi: 10.11648/j.aje.20200402.12

Received: July 31, 2020; Accepted: August 14, 2020; Published: August 31, 2020

\begin{abstract}
Phlebotomine sand flies (Diptera, Psychodidae, Phlebotominae) are small diptera that represent a group of approximately 1,000 known species around the world, of which 530 were found in the Americas. The females are hematophagous, a characteristic that makes them capable of participating in the transmission of etiological agents that cause diseases, such as leishmaniasis, bartonellosis, and arboviral diseases. Classical taxonomy requires knowledge of morphological and morphometric patterns for the correct classification and identification of species. In the classification and identification of sand flies it is common incomplete species descriptions, erroneous associations between sexes, as the existence of morphologically close or indistinguishable species, and polymorphic species make a correct diagnosis difficult. Another problem with classical taxonomy in sand flies is the occurrence of anomalies, which are generally observed in paired morphological structures. In September 2017 during surveillance for leishmaniasis in Iñapari Town, Peru, sand flies were captured using light traps for three consecutive nights. During entomological surveillance, 55 specimens were identified, including a female of Bichromomyia olmeca bicolor (Fairchild \& Theodor) showing an unusual structure not previously reported in sand flies. Within the median region of the scutum, a spine projection was observed, measuring $39.4 \mu \mathrm{m}$. The spine displayed a discrete surface convexity directed towards the anterior region of the thorax. Bilateral and unilateral anomalies have often been described in sand flies, mainly in structures that are under substantial evolutionary pressure, such as reproductive organs of males and females. The anomaly observed in Bi. olmeca bicolor is the first reported in the thorax of sand flies. An observation of similar anomalies from different species and in different countries shows the need for more studies to elucidate the causes for the occurrence of this phenomenon.
\end{abstract}


Keywords: Sand Fly, Vector Borne Diseases, Morphology, Thorax Spine

\section{Introduction}

The Psychodidae family has more than 3,000 described species worldwide [1]. This family is one of the most primitive of the order Diptera, with fossil records dating from the end of the Jurassic [2, 3] and the Upper Triassic [4]. Among the Psychodidae, sand flies Phlebotominae represent a group of approximately 1,000 known species around the world, of which 530 were found in the Americas [5]. These insects are holometabolic dipterans with cryptozoic habits. In these insects, only the females are hematophagous, a characteristic that makes them capable of participating in the transmission of etiological agents that cause diseases, such as leishmaniasis, bartonellosis, and arboviral diseases. To date, classical taxonomy, based on morphological and morphometric characterization of the external and internal structures of adult sand flies, has been the most used method in the classification of Phlebotominae. More sophisticated taxonomical approaches involving biochemical and molecular methods, require a complex infrastructure and sophisticated equipment for implementation. A classic taxonomic study, on the other hand, requires staff specially trained in the recognition of morphological and morphometric patterns for correct species classification and identification. This dependency on knowledgeable human resources results in incomplete species descriptions, erroneous associations between sexes, as the existence of morphologically close or indistinguishable species, and polymorphic species make a correct diagnosis difficult. Another problem with classical taxonomy in sand flies is the occurrence of anomalies, which are generally observed in paired morphological structures (bilateral or unilateral anomalies). The occurrence of anomalies in the male genitalia (gonostyles, parameres and epandrial lobes), female genitalia (spermathecae) and in the cibarium (female) has been reported for different species of sand flies [6-16].

\section{Materials and Methods}

Here we report the record of a morphological anomaly in a phlebotomine specimen from Peru. The observation was made in September 2017, in the town of Iñapari $\left(10^{\circ} 56^{\prime} 51.64^{\prime \prime} \mathrm{S}\right.$, $\left.69^{\circ} 34^{\prime} 35.04^{\prime \prime} \mathrm{W}\right)$, Tahuamanu province, in the region of Madre de Dios, Peru, during surveillance for leishmaniasis conducted through technical cooperation among the Interdisciplinary Entomological Surveillance Laboratory in Diptera and Hemiptera (Brazil), National Reference Laboratory for Leishmaniasis (Peru), and the Pan American Health Organization (PAHO). Iñapari has an area spanning $14,853.66 \mathrm{~km}^{2}$ along the border between Bolpebra (Bolivia) and Assis Brazil (Brazil). The bioclimate is humid lowland tropical forest, with an annual rainfall of 1,800 $\mathrm{mm}$, and a dry season between the months of May and October with annual temperatures averages of $24.8^{\circ} \mathrm{C}$, and temperatures average max and min of $35^{\circ} \mathrm{C} / 22^{\circ} \mathrm{C}$ respectively. According to the Köppen classification, Iñapari is classified as Aw [17]. Phlebotomine captures were made with Center for Disease Control (CDC) light trap [18] and modification on the CDC trap $[19,20]$ for three consecutive nights. Photographs of the specimen were taken with an AxioCam $\mathrm{ICc}^{\odot}{ }^{\odot}$ camera (Carl Zeiss Microscopy) coupled to a Primo Star Microscope (Carl Zeiss Microscopy). Morphological measurements were taken with 20X magnification using the Zen 2012 software $^{\odot}$ (Carl Zeiss Microscopy).

\section{Results and Discussion}

In total, 55 specimens of 11 sand fly species were identified using the identification of American taxa [21]. Among these specimens, a female of Bichromomyia olmeca bicolor (Fairchild \& Theodor) was noted during assembly and identification. The specimen presented an unusual structure not previously reported for phlebotomines. Within the median region of the scutum, a spine projection was observed, measuring $39.4 \mu \mathrm{m}$ with a base $11.5 \mu \mathrm{m}$ wide. The spine displayed a discrete surface convexity directed towards the anterior region of the thorax (towards the prescutum) (Table 1; Figure 1).

Table 1. Measurement in $\mu m$ of morphological characters associated with scutum anomalies of a female Bichromomyia olmeca bicolor and a male Lutzomyia diabolica.

\begin{tabular}{lll}
\hline Characters & $\begin{array}{l}\text { Bi. olmeca } \\
\text { bicolor ( ( +) }\end{array}$ & $\begin{array}{l}\text { Lu. diabolica } \\
\text { ( \&) })\end{array}$ \\
\hline Length of thorax & 513 & 579.8 \\
Length of spine & 39.4 & 60.4 \\
Width of base of spine & 11.5 & 34.6 \\
Midpoint on the thorax & 256.6 & 289.9 \\
$\begin{array}{l}\text { Distance between the midpoint of the base } \\
\text { of the spine and the midpoint of the thorax }\end{array}$ & - & 35.1 \\
\hline
\end{tabular}

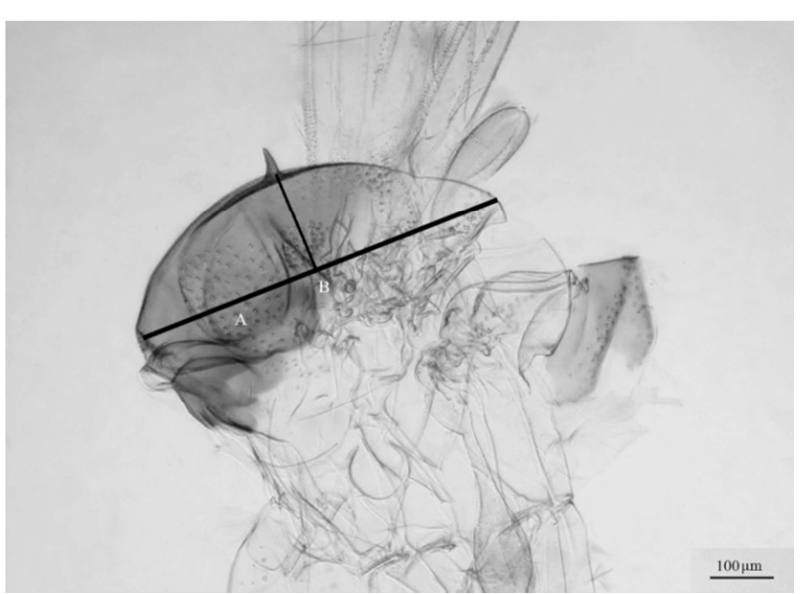

Figure 1. Morphological anomaly in the scutum of Bichromomyia olmeca bicolor (female) from Peru. A: length of thorax; B: midpoint on the thorax.

Galati [21] proposed a classification for the subfamily 
Phlebotominae with a phylogenetic approach. The subfamily was divided into the HERTIGIINI (Hertigiina and Idiophlebotomina subtribes) and PHLEBOTOMINI tribes. PHLEBOTOMINI was divided into the subtribes PHLEBOTOMINA, AUSTRALOPHLEBOTOMINA, BRUMPTOMYIINA, PSYCHODOPYGINA, LUTZOMYIINA and SERGENTOMYIINA where $B i$. olmeca bicolor belongs to the PSYCHODOPYGINA subtribe. Unilateral and bilateral anomalies in paired morphological structures of the genitalia (male/ female) and cibarium have been reported in multiple studies related to the classical taxonomy of Phlebotominae. In the male genitalia (gonostyles, parameres and epandrial lobes), additional or differentiated spines and or setae may occur in these structures. In gonostyles the anomalous spine can be bilateral or unilateral. This type of anomaly has been reported in Lutzomyia anduzei (=Lu. umbratilis (Nyssomyia umbratilis (Ward \& Fraiha)) and Lu. rorotaensis (Micropygomyia rorotaensis (Floch \& Abonnenc)) [6], 34 sand fly specimens belonged to 10 species of the Old World; [7], Lu. trinidadensis (Mi. trinidadensis (Newstead)) [8], Lu. intermedia (Nyssomyia intermedia (Lutz \& Neiva)) [9]; Lu. shannoni (Psathyromyia shannoni (Dyar)) [10], Phlebotomus papatasi (Scopoli) [11] and, Evandromyia evandroi [12]. Bilateral or unilateral anomalous setae in the parameres. This type of anomaly has been reported in $L u$. longipalpis (Lutz \& Neiva) [13, 14]. Bilateral or unilateral anomalous setae in the epandrial lobes. This type of anomaly has been reported in Ph. papatasi [11]. The female with teeth in the cibarium anomalies in Mi. trinidadensis, Pa. shannoni, Lu. lichyi (Floch \& Abonnenc), Lu. gomezi (Nitzulescu) [8] and, Lu. evansi (Pintomyia evansi (Nuñez-Tovar)) [15]. In the female genitalia the body of the anomalous spermathecae additional to the individual ducts in $P h$. longicuspis Nitzulescu [16].

Structures with unilateral anomalies are more easily identifiable than bilateral, as structures with bilateral anomaly can lead to an error in diagnosis if not observe other specific characters. As an example, based on the morphological and morphometric analysis of the male holotype, the taxonomic status of Ph. breviductus Barretto, was evaluated by Andrade, Shimabukuro and Galati [22]. After analysis, the authors concluded that the head and wing of the specimen belonged to Trichopygomyia sp., but the thorax and abdomen were from Ny. umbratilis, with the genitalia presenting an anomalous gonostyles with five spines. The holotype was composed of parts of specimens representing two different species and, therefore, $P h$. breviductus was considered an invalid species.

In 2017, as part of the technical cooperation, sand flies assembled on slides from Nicaragua were sent by the PAHO representative to confirm the diagnosis. Among the diagnosed species, a male of Lutzomyia diabolica was observed presenting an anomaly in the scutum, similar to that found in Bi. olmeca bicolor in Peru. Unlike Bi. olmeca bicolor, Lu. diabolica belongs to LUTZOMYIINA subtribe. Although the two subtribes are sibling groups, there is a big difference between the two subtribes and, even more, between the two species. At a specific level the pigmentation of the thorax segments is a character that can assist in the diagnosis. In both species, we can observe a distinct pigmentation between the scutellum in Bi. olmeca bicolor (Figure 1) and Lu. diabolica (Figure 2). Although the pigmentation of the scutellum is different in the two species, only this character in the thorax is not the only one to distinguish them, since both species have other characteristics belonging to their respective genera. In this male specimen, unlike in our female Bi. olmeca bicolor female, the spine was longer $(60.4 \mu \mathrm{m})$ and measured $35.1 \mu \mathrm{m}$ in the middle region of the scutum, with the convexity directed towards the posterior region of the thorax (towards the scutellum) (Table 1; Figure 2).

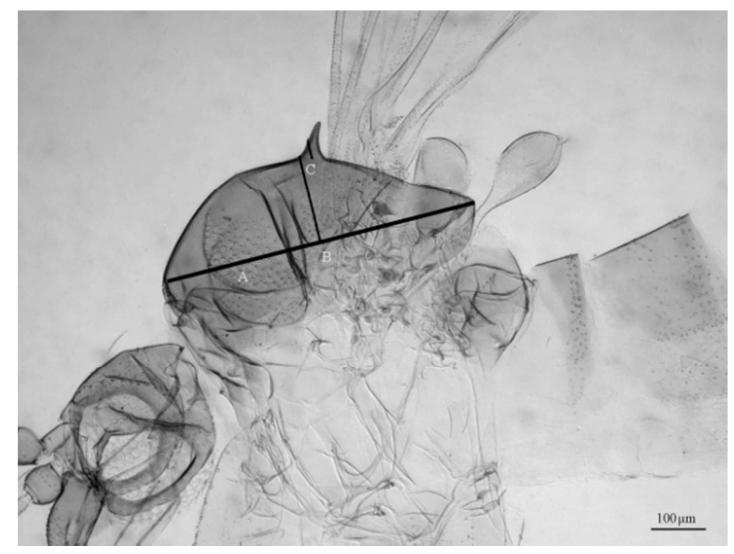

Figure 2. Morphological anomaly in the scutum of Lutzomyia diabolica (male) from Nicaragua. A: length of thorax; B: midpoint on the thorax; $C$ : distance between the midpoint of the base of the spine and the midpoint of the thorax.

\section{Conclusion}

The anomaly observed in Bi. olmeca bicolor is the first reported in the thorax of sand flies. The observation of similar anomalies in different species, countries and with different position, length and direction of the spines shows that this phenomenon should be better analyzed. Unlike the anomalies that occurred in gonostyles, parameres, epandrial lobes, cibarium and spermathecae, it does not influence the identification of the species because the character of taxonomic importance of thorax is its pigmentation. The population genetic structure of Bi. olmeca bicolor has not yet been studied, clearly showing that it needs to be evaluated. This anomaly out of the standard described in the literature needs to be investigated in order to know if the environment is being altered by climatic issues, anthropic action with destruction of the vegetation cover and may be influencing the morphological malformations occurring phenotypic variations. If there is an implication in the defense mechanism of the species or even because of these abiotic impact factors there is already a genetic character influencing the behavior of the gene.

\section{Acknowledgements}

We thank the biologists Ana Sophia Manrique Bautista and Antony Williams Alejo Mendiola, from the Vector Control 
Area of the Executive Directorate for Environmental Sanitation, Madre de Dios Regional Health Directorate and the veterinarians Rafaella Alburquerque e Silva of Communicable Disease Surveillance Department, Health Surveillance Secretariat, Ministry of Health, Brazil for their support in sand fly captures in the field in the district of Iñapari. To Dr. Catarina Macedo Lopes, Interdisciplinary Entomological Surveillance Laboratory in Diptera and Hemiptera, Oswaldo Cruz Institute, Brazil, by editing the figures.

\section{References}

[1] Pape, T.; Blagoderov, V.; Mostovski, M. B. 2011. Order Diptera Linnaeus, 1758. In: Zhang, Z.-Q. (Ed.). Animal biodiversity: An outline of higher-level classification and survey of taxonomic richness. Magnolia Press. Zootaxa, 3148: pp. 222-229.

[2] Ansorge, J. 1994. Tanyderidae and Psychodidae (Insecta: Diptera) from the Lower Jurassic of northeastern Germany. Paläontologische Zeitschrift 68: 199-210.

[3] Grimaldi, D.; Engel, M. S 2005. Evolution of the Insects. Cambridge University Press, New York, 772p.

[4] Blagoderov, V.; Grimaldi, D. A.; Fraser, N. C. 2007. Diverse Diptera from the Triassic of Virginia and Early Radiation of the Order. American Museum Novitates 3572: 1-39.

[5] Shimabukuro, P.H.F., de Andrade A.J., Galati, E.A.B. 2017. Checklist of American sand flies (Diptera, Psychodidae, Phlebotominae): genera, species, and their distribution. Zookeys. 8: 67-106.

[6] Almeida, F.B. 1970. Flebótomos da Amazônia II. Sobre ocorrência de anomalia na genitália masculina em Lutzomyia anduzei (Rozeboom, 1942) e Lutzomyia rorotaensis (Floch \& Abonnenc, 1944) (Diptera: Psychodidae). Bol. do INPA. Serie: Patologia Tropical: 1: 1-4.

[7] Abonnenc, E.; Poinsot, S.; Rioux, J. A. 1971. Teratologie des Phlebotomes (Diptera: Psychodidade) revision et nouvelles observations. Cahiers ORSTOM. Série Entomologie Medicale et Parasitologie 9: 307-316.

[8] Feliciangeli, M. D.; Ordones, R.; Aguilar, C. M. 1985. Anomalies of sandflies inVenezuela. Acta Amazonica 15: 157-166.

[9] Marcondes, C. B. 1999. Anomalies of Lutzomyia intermedia (Lutz \& Neiva, 1912) (Diptera, Psychodidae, Phlebotominae). Memórias Instituto Oswaldo Cruz 94: 365-366.

[10] Florin, D. A., Lawyer, P., Rowton, E., Schultz, G., Wilkerson, R., Davies, S. J., Lipnick, R., Keep, L. 2010. Morphological Anomalies in Two Lutzomyia (Psathyromyia) shannoni (Diptera: Psychodidae: Phlebotominae) Specimens Collected From Fort Rucker, Alabama, and Fort Campbell, Kentucky. J. Med. Entomol. 47: 952-956.
[11] Guernaoui, S., Ramaoui, K., Rahola, N., Barnabe C., Sereno D., Boumezzough, A. 2010. Malformations of the genitalia in male Phlebotomus papatasi (Scopoli) (Diptera: Psychodidae). Journal of Vector Ecology 35: 13-19.

[12] Costa, P. L.; Silva, F. L.; Andrade-Filho, J. D.; Shaw, J. J.; Filho, S. P. B. 2012. Bilateral anomaly in Evandromyia evandroi (Diptera, Psychodidadae, Phlebotominae) captured in Vicência Municipality, northern rainforest region of Pernambuco State, Brazil. Journal of the American Mosquito Control Association 28: $128-130$.

[13] Ximenes, M. F. F. M.; Castellón, E. G.; Freitas, R. A. 2002. Morphological genitalic anomaly in Lutzomyia longipalpis sensu lato (Lutz \& Neiva, 1912) collected in the State of Rio Grande do Norte, Brazil. Boletín Entomología Venezolana 17: 183-184.

[14] Sanguinette, C. C.; Faustino, J. X.; Serra-e-Meira, P. C. L.; Botelho, H. A.; Carvalho, G. M. L.; Gontijo, C. M. F.; Andrade Filho, J. D. 2013. Anomalies in the sand fly Lutzomyia longipalpis (Diptera: Psychodidae) in Brazil. Journal of the American Mosquito Control Association 29: 54-58.

[15] Daboín, Y. M., Oviedo-Araújo, M., González-Pérez, A., Suárez-Hernández, J., Sandoval, C. M., Cazorla, D. 2015. Anomalías morfológicas en los dientes del cibario de Lutzomyia evansi (Diptera: Psychodidae) en el estado Trujillo, Venezuela. Biomédica 35: 269-73.

[16] Chemkhi, J., Guerbouj, S., Guizani, I., Salah, A. B. 2015. First Report of Abnormal Spermathecae in Phlebotomus (Larroussius) longicuspis Nitzulescu, 1930 (Diptera: Psychodidae), in Tunisia. Journal of Life Sciences 9: 465-471.

[17] Zambrano, A. M. A.; Broadbent, E. N.; Schmink, M., Perz; S. G., Asner, G. P. 2010. Deforestation Drivers in Southwest Amazonia: Comparing Smallholder Farmers in Inãpari, Peru, and Assis Brasil, Brazil. Conservation and Society 8: 157-170.

[18] Sudia, W. D.; Chamberlain, R. W. 1962. Battery operated light trap, an improved model. Mosquito News 22: 126-129.

[19] Gomes, A. C., Rabello, E. X., Natal, D. 1985. Uma nova câmara coletora para armadilha CDC- miniatura. Rev. Saúde Públ. 19: 190-191.

[20] Pugedo H, Barata RA, França-Silva JC, Silva JC, Dias ES (2005) HP: um modelo aprimorado de armadilha luminosa de sucção para captura de pequenos insetos. Rev. Soc. Bras. Med. Trop. 38: 70-72.

[21] Galati, E. A. B. 2018. Phlebotominae (Diptera, Psychodidae): Classification, Morphology and Terminology of Adults and Identification of American Taxa. In Rangel, E. F., Shaw, J. J. (Ed.). Brazilian Sand Flies: Biology, Taxonomy, Medical Importance and Control. Rio de Janeiro., Ed. Springer, pp: 9-212.

[22] Andrade, A. J, Shimabukuro, P. H. F; Galati E. A. B, plazi 2013. On the taxonomic status of Phlebotomus breviductus Barretto, 1950 (Diptera: Psychodidae: Phlebotominae). Plazi.org taxonomic treatments database. Checklist dataset https://doi.org/10.11646/zootaxa.3734.4.5 accessed via GBIF.org on 2020-07-21. 